\title{
The Theory of Planned Behavior and Self-Identity Factors Drive Graduates to Be Indebtedness
}

\author{
Zarina Denan, Akmal Aini Othman, Muhammad Noor Izami Ishak, Mohd Fazril Mustaza Kamal, and \\ Muhammad Hanif Hasan
}

\begin{abstract}
This study investigates the factors affecting borrowing intention among fresh graduates of Malaysia based on the Theory of Planned Behavior (TPB). About 153 questionnaires were accepted and analyzed using structural equation modeling (SEM) in determining the relationships. The results show that borrowing intention amongst fresh graduates is influenced by self-identity and perceived behavior control. The young graduates believe that they have complete control of their behavior in borrowing as they perceived to be equipped with the knowledge about the personal financing. In addition, because of their experience in students' loans since undergraduates' level, the result explains why self-identity was found to be a significant predictor. The findings offer implications for researchers and government.
\end{abstract}

Index Terms-Borrowing, self-identity, theory planned behavior.

\section{INTRODUCTION}

Each year the number of graduates in Malaysia is increasing in numbers as a result of the expansion of educational services in Malaysia with 12 public universities and many more private colleges. Many graduates are employed within the first six months after graduating. The current salaries paid to the graduates are quite competitive as compared to a few years back. However, many university graduates have been declared bankrupt by Department of Insolvency of Malaysia due to heavy credit card spending and loans default. The percentage of bankrupts increases by 5 percent every 5 years and the number is expected to reach 120,000 by 2020 . This alarming figures of debt amongst graduates are serious matter because inability to manage financial resources which lead to several other problems.

This issue has raised many questions as graduates are facing the debt situation since entering the higher education institution. This situation continues until they complete their studies and enter the job market. What has driven the young graduates to be indebtedness will be investigated by applying theory planned behaviour. Thus, this study is trying to investigate factors which influence borrowing from the financial institutions by applying the theory of planned behaviour as the underlying theory.

Manuscript received November 25, 2013; revised January 20, 2014.

Zarina Denan is with the Universiti Teknologi Mara, Malaysia (e-mail: zarin424@salam.uitm.edu.my)

\section{LITERATURE REVIEW}

\section{A. Theory Planned Behavior}

The theory of planned behavior (TPB) is an extension of the theory of reasoned action (TRA) made necessary by the original model's limitations in dealing with behaviors over which people have incomplete volitional control [1]. Both TPB and TRA have similar objectives to understand the human behavior through identifying and analyzing the determinants of behavioral intentions. Ajzen introduced TPB in an attempt to provide a better conceptual framework of behavior by addressing TRA's problem of incomplete volitional behavior. The TPB postulates that the actual behavior is the weighted functions of behavioral intention and perceived behavioral control. In turn, a behavioral intention is the weighted function of attitude towards the behavior (attitude), Subjective norm, and perceived behavioral control [2]. The TPB has been used to investigate human behaviors from favorable behaviors (such as technology adoption, halal food purchasing) to unfavorable behaviors (such as theft and shoplifting).

The application of TPB in Malaysian context also had been widely use in the field of research. In consumer research behavior, [3] used the TPB adapted from Ajzen's Theory of Planned Behavior with the aim of extending prior research examining halal food purchasing behavior in Malaysia. Their study examined the halal food purchasing behavior, identifying the rationales for purchasing of halal foods. [4] used the TPB model to understand speeding and interventions in school zones in Malaysia and Australia because speeding is usually an intentional behavior. However, they suggested an improvement to the explanatory value of the TPB by taking account unintentional speeding attributable to a lack of focus on important elements of the driving environment. While, [5] explored the factors that encourage students to adopt social network sites (SNS) in Malaysia and to use the findings to develop guidelines for SNS providers on how to maximize the rate of adoption. TAM, TPB and intrinsic motivation is proposed and empirically tested in the context of SNS usage. Saifullah \& Mohamad (2010) aimed to identify some factors that affected the adoption of M-commerce in the Klang Valley of Malaysia by developing M-commerce adoption models based on traditional technology model such as TRA, TPB, TAM and Diffusion Innovation theory (DOI). [6] identified factors that influenced student's intention to become an entrepreneur based on the model TPB. This study implied that the TPB 
model is capable of predicating student's intention towards entrepreneurship, and further explained the students' decision to become an entrepreneur in the future.

All the research cited above supported TPB model in predicting and explaining the intention behavior in various areas in the Malaysia context. The application of TPB in this study aims to understand borrowing intentions amongst fresh graduates seemed appropriate.

The above research have used the original variables from TPB by Ajzen [1] which include attitude, perceived behavior control and subjective norm as the predicting variables. This study adopts the original framework from Ajzen [1] and adds one more variable which is self-identity to predict borrowing intention amongst graduates in Malaysia.

Attitude is regarded as individual's positive or negative evaluation of the behavior [2]. Attitude as hypothesized by Fishbein and Ajzen (1975) is associated with behavioral intention and leading to the actual behavior. Perceived behavior control refers to the perceived ease or difficulty of performing the behavior and the amount of control one has over the attainment of the goals from said behavior [7]. According to [8] perceived behavioral control is positively associated with the personal confidence in the ability to complete a task and overcome challenges. Subjective norm refers to individual's perceptions of social pressure to perform or not to perform the behavior [2]. This means if an individual perceives that people important to him/her approve (or disapprove) of a behavior, the individual is more (or less) likely to intend to perform it. Self-identity describes the social groups or social categories that someone belongs to [9]. Rise, [10] posit there is a possibility that self-identity may simply reflect past performance of a behavior which the argument is that people understand what kind of persons they are by making inferences based on their past behavior.

The four variables (attitude, perceived behavior control, subjective norm and self-identity) are hypothesized to have a positive association with borrowing intention. Borrowing in this study refers to a loan which is a debt evidenced by a note which specifies, among other things, the principal amount, interest rate, and date of repayment [11]-[16].

\section{B. Hypotheses}

- H1: Borrowing intention of fresh graduates is associated with their attitude.

- H2: Borrowing intention of fresh graduates is associated with their perceived behavior control.

- H3: Borrowing intention of fresh graduates is associated with their subjective norm.

- H4: Borrowing intention of fresh graduates is associated with their self-identity.

\section{Methodology}

This study focused only on one public university which has the highest population and graduates in Malaysia. About 153 questionnaires were returned and analyzed. The age of respondents is between 23-30 years old. In terms of marital status, $92 \%$ of the respondents are still single. $84 \%$ of the respondents have one year working experience and another $16 \%$ of them have been working between $2-5$ years. About
$85 \%$ of the respondents are working with private sector while $15 \%$ of them are working with the government.

\section{RESUlTS AND DiscUSSION}

The sequence of analysis took the following order: firstly, exploratory factor analysis (EFA) was performed on each measurement model to assess unidimensionality in terms of the parameter estimates, the statistical significance of the parameter estimates and overall fit. Upon inspecting the results, at this point the researcher then decided whether to retain or delete any ill-fitting item.

Secondly, CFA was performed on those measurement models that were comprised of purified measures derived from the first step. Finally, all pertinent results on the measurement models were presented in Fig. 1.

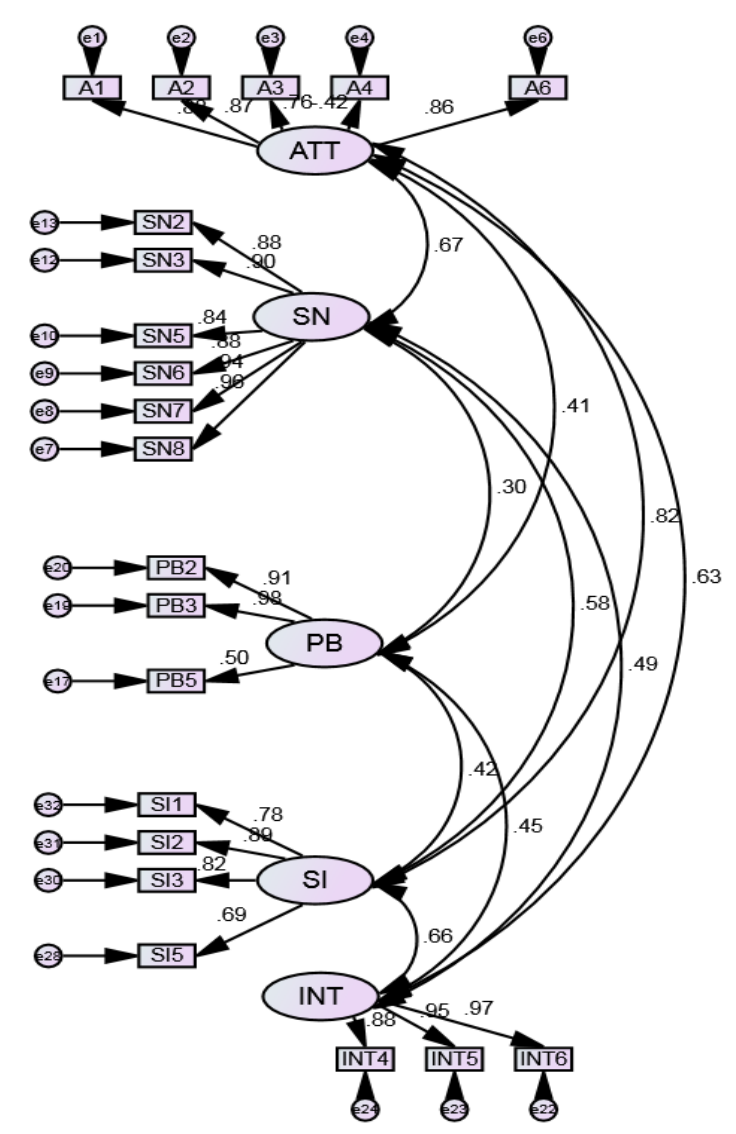

Note: ATT- Attitude; SN - Subjective Norm; PB - Perceived Behavioural Control; SI - Self Identity; INT - Intention

Fig. 1. Measurement model.

Fig. 2 exhibits the results of the factor loading (standardised regression weights) between latent variables and their indicators as well as the scores of correlations between variables the result indicates that all items loadings are statistically significant and the magnitude for most of the variables and their indicators are above reasonable benchmark. With regards to the score for the correlations, the scores indicate the correlations are between the ranges of 0.3 to 0.82 . Overall, the value of both reliability and convergence validity tests imply reliable scores for those latent constructs used in this study. 


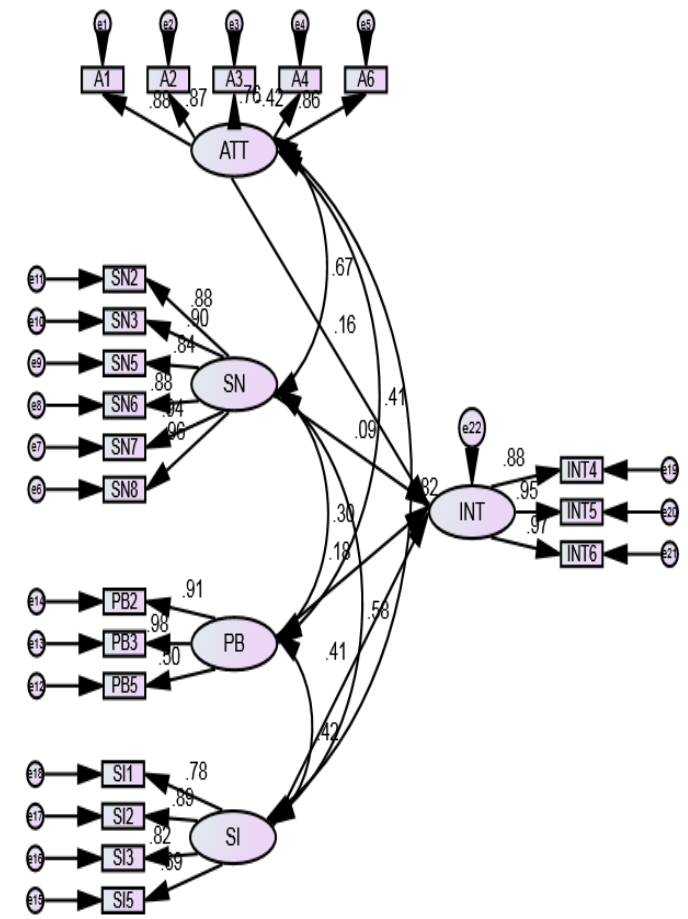

Note: ATT- Attitude; SN - Subjective Norm; PB - Perceived Behavioural Control; SI - Self Identity; INT - Intention

Fig. 2. Result of the path model relationships.

The effect of importance and acceptance, acceptance with government sincere initiatives and political incentives were performed. Results of the standardized parameter estimates of the proposed model were depicted in Table I respectively. The results showed that RMSEA $=0.091, \mathrm{CMIN} / \mathrm{DF} 2.699$, IFI 0.928 , TLI 0.9145 CFI .927, indicating a good fit between the data and the proposed model. The statistical significance of the structural parameters was examined and it was found that all the hypotheses were supported except for the relationships between acceptance and political motives.

TABLE I: OVERALL STANDARDIZED PARAMETER ESTIMATES FOR THE STRUCTURAL MODEL

\begin{tabular}{|c|c|c|c|c|c|}
\hline $\begin{array}{l}\text { Hypo- } \\
\text { theses }\end{array}$ & $\begin{array}{l}\text { Path } \\
\text { relationships }\end{array}$ & $\begin{array}{l}\text { Sig. } \\
\text { level }\end{array}$ & $\begin{array}{l}\text { Parameter } \\
\text { Estimates }\end{array}$ & $\begin{array}{c}\text { p-values } \\
(\leq 0.05)\end{array}$ & $\begin{array}{c}\text { Sig. } \\
\text { (yes/no) }\end{array}$ \\
\hline H1 & $\begin{array}{l}\text { Attitude - } \\
\text { Intention }\end{array}$ & 0.05 & 0.155 & 0.225 & No \\
\hline $\mathrm{H} 2$ & $\begin{array}{l}\text { Subject Norm } \\
\text { - Intention }\end{array}$ & 0.05 & 0.092 & 0.222 & No \\
\hline $\mathrm{H} 3$ & $\begin{array}{l}\text { Perceived } \\
\text { Behavioural } \\
\text { Control - } \\
\text { Intention }\end{array}$ & 0.05 & 0.183 & 0.001 & Yes \\
\hline & $\begin{array}{l}\text { Self Identity - } \\
\text { Intention }\end{array}$ & & & & \\
\hline
\end{tabular}

The findings of the analytical model indicate that the significant factors influencing borrowing intention include perceived behavior control and self-identity. This study provides some indicators to the government and financial institutions that graduates need help in terms of managing their personal financing and culture of saving and investing in education need to be instilled and promoted in the future generations to avoid being indebtedness. Other measure to be considered may include tightening the policy of borrowing.

\section{REFERENCES}

[1] I. Ajzen, "The theory of planned behavior," Organizational Behavior and Human Decision Processes, vol. 50, pp. 179-211, 1991.

[2] A. Yayla and Q. Hu, "User acceptance of e-commerce technology: A meta-analytic comparison of competing models," presented at ECIS 2007, St Gellen, Switzerland, September 10-14, pp. 179-190.

[3] S. S. Alam and N. M. Sayuti, "Applying the theory of planned behavior (TPB) in halal food purchasing," International Journal of Commerce and Management, vol. 21, iss: 1, pp. 8-20, 2011.

[4] A. Hanan, S. King, J. Mark, and M. L. Ioni, "Understanding speeding in school zones in Malaysia and Australia using an extended theory of planned behavior: the potential role of mindfulness," Journal of the Australasian College of Road Safety, vol. 22, no. 2, pp. 56-62, 2011.

[5] S. L. Goh, S. Lada, M. Z. Muhammad, A. A. H. A. Ibrahim, and T. Amboala, "An exploration of social networking sites (SNS) adoption in Malaysia using technology acceptance model (TAM), theory of planned behavior (TPB) and intrinsic motivation," Journal of Internet Banking and Commerce, vol. 16, no. 2, 2011.

[6] A. H. M. Ariff, Z. Bidin, Z. Sharif, and A. Ahmad. "Predicting entrepreneurship intention among Malay University Accounting students in Malaysia," UNITAR E-Journal, vol. 6, no. 1, 2010.

[7] T. Teo and C. B. Lee, "Explaining the intention to use technology among student teachers: An application of the Theory of Planned Behavior (TPB)," Campus-Wide Information Systems, vol. 27, no. 2, pp. 60-67, 2010.

[8] H. Y. Lu, H. Y. Hou, T. H. Dzwo, Y. C. Wu, J. E. Andrews, S. T. Weng, and J. Y. Lu, "Factors influencing intentions to take precautions to avoid consuming food containing dairy products: Expanding the theory of planned behavior," British Food Journal, vol. 112, no. 9, pp. 919-933, 2010.

[9] B. V. D. Putte, M. C. Willemsen, M. Yzer, and G. J. D. Bruijin, "The effects of smoking self-identity and quitting self-identity on attempts to quit smoking," Journal of Health Psychology, vol. 28, no. 5, pp. 535, 2009.

[10] J. Rise, P. Sheeran, and S. Hukkelberg, "The role of self-identity in the theory of planned behavior: A meta-analysis," Journal of Applied Social Psychology, vol. 40, no. 5, pp. 1085-1105, 2010b.

[11] Insolvency. M. D. o. (n.d.). What is personal bankruptcy. Personal Bankruptcy. [Online]. Available: http://www.insolvensi.gov.my/about-us/core-business/core-business/p ersonal-bankruptcy

[12] P. Sparks and C. A. Guthrie, "Self-identity and the theory of planned behavior: A useful addition or an unhelpful artifice?" Journal of Applied Social Psychology Qu, vol. 28, no. 15, pp. 1393-410, 1998.

[13] A. A. Bailey, "Retail employee theft: a theory of planned behavior perspective," International Journal of Retail and Distribution Management, vol. 34, no. 11, pp. 802-816, 2006.

[14] J. S. S. Zhen and S. Mansari, "Young female motivations for purchase organic food in Malaysia," International Journal of Contemporary Business Studies, vol. 3, no. 5, pp. 61-72, 2012.

[15] A. H. M. S. Sadi and M. F. Noordin, "Factors influencing the adoption of m-commerce: An exploratory analysis," in Proc. 2011 International Conference Industrial Engineering and Operations Management, Kuala Lumpur, Malaysia, January 22-24, 2011.

[16] C. L. Wong and B. A. Mullan, "Predicting breakfast consumption: An application of the theory of planned behaviour and the investigation of past behaviour and executive function," British Journal of Health Psychology, vol. 14, pp. 489-504, 2009.

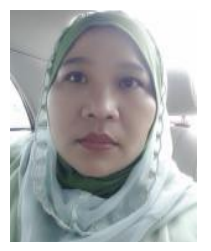

Zarina Denan is a senior lecturer at Faculty of Business Management, Universiti Teknologi Mara, Malaysia. She holds a $\mathrm{PhD}$ in business management specializing in knowledge management in small medium enterprises (SMEs). Her research focuses on area of economics development, entrepreneurship and knowledge management.

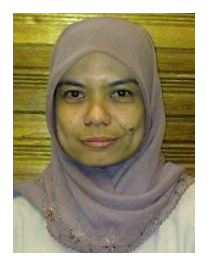

Akmal Aini Othman is currently the head of Learning Centre at the Faculty of Business Management, University Teknologi Mara Johor Malaysia. She holds a $\mathrm{PhD}$ in business management specialising in the procurement process and marketing resources in the building construction industry. Her research interests include issues surrounding supply chain Management, Relationship Marketing, construction management as well as training and development. 


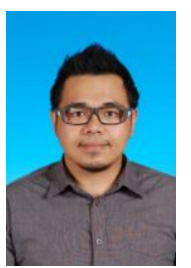

Muhammad Noor Izami bin Ishak is a graduate of masters of business administration from Arshad Ayub Graduate Business School, Universiti Teknologi Mara, Malaysia. Currently, he is working as a bank officer at CIMB Bhd.

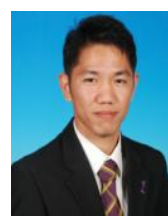

Muhammad Hanif Hasan is a graduate of masters of business administration from Arshad Ayub Graduate Business School, Universiti Teknologi Mara, Malaysia. Currently, he is working as an executive \& sales marketing at Alloy Advertising Sdn Bhd.

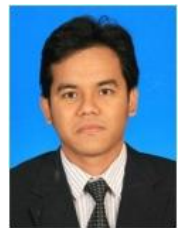

Mohd Fazril bin Mustaza Kamal is a graduate of masters of business administration from Arshad Ayub Graduate Business School, Universiti Teknologi Mara, Malaysia. Currently, he is working as an application engineer at Intergraph Process Power \& Offshore (M) Sdn Bhd. 